\title{
The effect of water turbidity on the near-surface water temperature of larval habitats of the malaria mosquito Anopheles gambiae
}

\author{
K. P. Paaijmans • W. Takken • A. K. Githeko • \\ A. F. G. Jacobs
}

Received: 13 November 2007 / Revised: 24 April 2008 / Accepted: 8 May 2008 / Published online: 17 July 2008

(C) The Author(s) 2008

\begin{abstract}
Water temperature is an important determinant in many aquatic biological processes, including the growth and development of malaria mosquito (Anopheles arabiensis and A. gambiae) immatures. Water turbidity affects water temperature, as suspended particles in a water column absorb and scatter sunlight and hence determine the extinction of solar radiation. To get a better understanding of the relationship between water turbidity and water temperature, a series of semi-natural larval habitats (diameter $0.32 \mathrm{~m}$, water depth $0.16 \mathrm{~m}$ ) with increasing water turbidity was created. Here we show that at midday (1300 hours) the upper water layer (thickness of $10 \mathrm{~mm}$ ) of the water pool with the highest turbidity was on average $2.8^{\circ} \mathrm{C}$ warmer than the same layer of the clearest water pool. Suspended soil particles increase the water temperature and furthermore change the temperature dynamics of small water collections during daytime, exposing malaria mosquito larvae, which live in the top water layer, longer to higher temperatures.
\end{abstract}

K. P. Paaijmans • A. F. G. Jacobs

Meteorology and Air Quality, Wageningen University,

Wageningen, The Netherlands

K. P. Paaijmans $\cdot$ W. Takken

Laboratory of Entomology, Wageningen University,

Wageningen, The Netherlands

\section{A. K. Githeko}

Kenya Medical Research Institute,

Climate and Human Health Research Unit,

Kisumu, Kenya

Present address:

K. P. Paaijmans $(\square)$

Center for Infectious Disease Dynamics/Entomology Department,

Pennsylvania State University,

19A Chemical Ecology Lab,

University Park, PA 16802, USA

e-mail: krijn@paaijmans.nl
Keywords Water temperature dynamics · Suspended particles $\cdot$ Aquatic insect ecology $\cdot$ Malaria mosquito immatures $\cdot$ Shallow water puddles

\section{Introduction}

The diurnal, monthly or even annual cycle of the water temperature is very important in many aquatic biological processes involving plants, microbes as well as animals inhabiting the water. Water temperature is certainly an important determinant in the growth and development of the immatures of two malaria mosquito species Anopheles arabiensis Patton and A. gambiae Giles sensu stricto (hereafter referred to as A. gambiae). They both belong to the $A$. gambiae Giles sensu lato complex (hereafter referred to as $A$. gambiae s.l.) and occur sympatrically across a wide range of tropical Africa, where they are the most effective vectors of malaria parasites (Coetzee et al. 2000). The larvae of both species develop in small, shallow, open and sunlit water collections (Gillies and DeMeillon 1968; Le Sueur and Sharp 1988; Gimnig et al. 2001), such as borrow pits, brick pits, tire tracks, small puddles, human foot and animal hoof prints. These water bodies are often of a transient nature, as their availability corresponds to rainfall (Gimnig et al. 2001; Fillinger et al. 2004; Koenraadt et al. 2004) and can be clear or turbid (Robert et al. 1998; Minakawa et al. 1999; Gimnig et al. 2001; Sattler et al. 2005; Mwangangi et al. 2007).

Turbidity, defined as 'an expression of the optical properties of a sample that causes light rays to be scattered and absorbed rather than transmitted in straight lines through the sample' (ASTM 2000) will change the water temperature as suspended particles in a water column absorb and scatter sunlight and hence determine the extinction of solar radiation. Particles such as clay and silt, finely divided 
organic matter, plankton and micro-organisms contribute to turbidity. Rises in water turbidity are promoted by downhill movement of runoff that detaches and carries soil and sediment into water bodies. Moreover, the turbidity can be increased by biological activity, such as increasing algal matter and phytoplankton abundance, or by the disturbance of water pools by humans (e.g. in road puddles or water collection sites) or animals (e.g.. in puddles near cattle).

Apart from changing the water temperature, which will change larval development rate and survival (Lyimo et al. 1992; Bayoh and Lindsay 2003, 2004), there are several other ways in which water turbidity can affect mosquito immatures. First, it may alter their distribution as females of A. gambiae s.l. seem to prefer darker substrates (McCrae 1984; Huang et al. 2005, 2007) or substrates turbid with soil over clear water (McCrae 1984; Minakawa et al. 1999) to deposit their eggs on. Second, a preference for turbid water can be advantageous as a higher turbidity may decrease the chance of being preyed upon due to a lower visibility. Predation is often considered to be an important factor explaining the high mortality rates that are observed in natural breeding sites (Service 1973, 1977; Lyimo 1993; Mwangangi et al. 2006). Third, particles that contribute to turbidity may also directly interfere with larval feeding and, hence, slow larval growth and decrease larval survival, as is suggested by Ye-Ebiyo et al. (2003).

A change in the efficiency of light penetration through a water body and in the water temperature will furthermore alter the abundance of algae. Algae are important food sources for A. gambiae s.l. larvae and possible regulators of larval populations (Gimnig et al. 2002; Tuno et al. 2006) and algal growth is favored by higher temperatures and more light (Kirk 1994). Indirectly, a lower light regime in water bodies can increase algal biomass by affecting the submerged aquatic plants, as light is a major factor limiting submerged macrophytes (Kirk 1994). Macrophytes can suppress algal growth by a reduction in available nutrients (Van Donk et al. 1990) and by allelopathy, the secretion of substances that are toxic to algae (see review in Gross 2003). This might explain the observations by Gimnig et al. (2001) that larvae of $A$. gambiae s.l. were associated with habitats that contained algae but little or no vegetation.

Higher water temperatures in turbid water pools will also result in a more rapid evaporation and hence decrease the longevity of the pools. In very small and turbid water collections, this means that the mosquito immatures will have a relative shorter time span to reach the adult stage. For example, under ambient conditions in the field, development of $A$. gambiae s.l. larvae into adults may take as little as one week, but as long as three weeks (Jepson et al. 1947; Gimnig et al. 2002). Successful A. gambiae s.l. maturation necessitates the continuous presence of water in the breeding site for at least this time period, although larvae are known to survive for a few days on damp soil (Koenraadt et al. 2003).

To our knowledge, the relationship between water turbidity and water temperature in very shallow water bodies has not previously been studied. In larger water systems, turbidity is known to change the water temperature. In seas, for example, a high turbidity changes the sea surface temperature (SST), and model simulations of the SST should include turbidity to account for variations in solar radiation extinction (Kara et al. 2004). Kara et al. (2005) demonstrated that using a clear-water constant attenuation depth assumption as opposed to turbid water type to model the SST of the Black Sea, resulted in monthly SST biases as large as $3^{\circ} \mathrm{C}$ in the summer period. However, these water systems are much larger and deeper than the water pools malaria mosquitoes use for breeding, and water temperatures are averaged over a larger time scale, whereas weeks or even days are important in larval mosquito ecology. Therefore this study focuses on the effect of water turbidity on the near-surface water temperature of small and shallow semi-natural water bodies in Kenya over a few days.

\section{Materials and methods}

The experiment was carried out in May 2006, in the grounds of the Kenya Medical Research Institute (KEMRI) near Kisumu, Kenya. The experimental area consisted of black cotton soil and was covered with grass, which was kept short. Semi-natural pools of water were created by digging holes $(\varnothing 0.32 \mathrm{~m}$, depth $0.17 \mathrm{~m})$ in the soil, at least $0.3 \mathrm{~m}$ apart. The holes were lined with transparent plastic $(0.13 \mathrm{~mm})$, which was pressed tightly against the soil to maximize plastic-soil contact and kept in place by a small metal ring (diameter $50 \mathrm{~mm}$ larger than the water pool).

One pit was filled with clear tap water up to $10 \mathrm{~mm}$ under the rim (site no. 1). The water originated from a well at the KEMRI grounds. Eight other pits were filled with water of different turbidity. Red clay soil was collected in the vicinity of Maseno ( $25 \mathrm{~km}$ northwest of Kisumu), sundried and fine clay particles of up to $1 \mathrm{~mm}$ in diameter were selected by sieving the soil through a sieve with mesh size of $1 \mathrm{~mm}$. The highest turbidity in the gradient series was created by adding $5.8 \mathrm{~kg}$ of friable clay soil to 851 of tap water. The mixture of water and soil was stirred for $30 \mathrm{~s}$, after which the surplus soil was allowed to settle at the bottom of the basin for $10 \mathrm{~min}$. Part of the supernatant was used to fill one pit (site no. 9) and the remainder was mixed with clear tap water in a 3:1 ratio, stirred again for $30 \mathrm{~s}$, after which another pit was filled (site no. 8). The dilution and mixing of the solution and the subsequent filling of a hole was continued until all semi-natural pools of water 
were filled. The water bodies of different turbidity were randomly distributed over the experimental area.

Daily at 0900, 1300 and 1700 hours, the water temperature of the upper $10 \mathrm{~mm}$ of each pool of water was measured in the center with a handheld digital thermometer (GTH 175/Pt; Greisinger Electronic, Germany). The part of the probe above the air-water interface was shielded from direct sunlight by a white polystyrene cover. Subsequently, the water turbidity (1) of the top $10 \mathrm{~mm}$, (2) halfway the pool, and (3) of the bottom $10 \mathrm{~mm}$ was measured in the centre of each pool with a portable Turbidimeter (TN100; Eutech Instruments, Singapore) in nephelometric turbidity units (NTU).

Each morning before 0800 hours clear tap water was added to the pools of water to compensate for evaporation and to maintain a uniform water level, after which all pools were stirred thoroughly for $15 \mathrm{~s}$ to create a homogeneous turbidity. The experimental setup was covered during the evening and night to prevent rainfall from disturbing the experiment. Once a week, all pools were emptied, the plastic lining cleaned and, subsequently, the pits were refilled with clear or turbid water.

Eleven days were selected for the study. The relationship between water turbidity and the near-surface water temperature is discussed in more detail for two separate but consecutive days, which differed in the daily incoming solar radiation load. This is because the water turbidity and water temperature of the pools in the morning, as well as the climatic conditions throughout the day, varied per experimental day, as the experiments were carried out under natural weather conditions outdoors. The first day (25 May 2006) was a clear day; the second day (26 May 2006) an overcast day. The incoming shortwave radiation was measured at $1.5 \mathrm{~m}$ above ground (Type CM11; Kipp \& Zonen, The Netherlands). Data were averaged at 15-min intervals and stored in a 21x Microdatalogger (Campbell Scientific, U.K.).

Data were analyzed using SPSS software (version 12.0.1, SPSS, Chicago, IL). A General Linear Model (GLM) was used to test for the effect of "measurement depth", "water pool" or for an interaction between "measurement depth $\times$ water pool" on the water turbidity. Experimental series was included in the GLM as a random factor and a double square root transformation was used for water turbidity to meet normality assumptions. The correlation between water turbidity and water temperature over the selected period of 11 days is calculated with Spearman's rank correlation test. Linear regression and ANOVA were used to test the statistical significance of the relationship between turbidity and temperature on the two selected days. The time mentioned in this paper is the local Kenyan time (UTC+3 h).

\section{Results}

Water turbidity over water depth

Considering the data collected at 1300 hours, water turbidity varied significantly between the experimental pools $\left(F_{8,260}=\right.$ 613.8, $P<0.001)$. In general, the water layer near the bottom was more turbid than the top water layer $\left(F_{2,260}=69.9\right.$, $P<0.001)$ and, as there was a strong interaction between water layer and experimental pool $\left(F_{16,260}=5.8, P<0.001\right)$, this difference seemed to increase when the average turbidity of a pool increased (Fig. 1). This difference was not observed in the clear and near-clear pools.

Water turbidity versus water temperature

Figure 2 shows all recorded data points during the study period. Although accumulating all data results in deviations in water temperature in relation to water turbidity, due to different daily experimental conditions as mentioned in the "Materials and methods", there were significant correlations between water turbidity and the near-surface water temperature of a pool. During midday (1300 hours), water temperature increased with increasing turbidity $(\rho=0.58$, $P<0.001)$, whereby the difference between the clearest and most turbid pool was on average $2.8^{\circ} \mathrm{C}( \pm 0.2$ S.E.M.; range 1.0-3.3). At 1700 hours, a decrease in water temperature with increasing water turbidity was observed $(\rho=-0.36, P=$ $0.002)$ and the difference between the clearest and most turbid pool was on average $0.3^{\circ} \mathrm{C}( \pm 0.1$; range $-1.2-0.0)$. No significant correlation was recorded at 0900 hours. Subsequently, Fig. 2 shows that daily turbidity of the pools decreased over time; the turbidity readings at 1700 hours

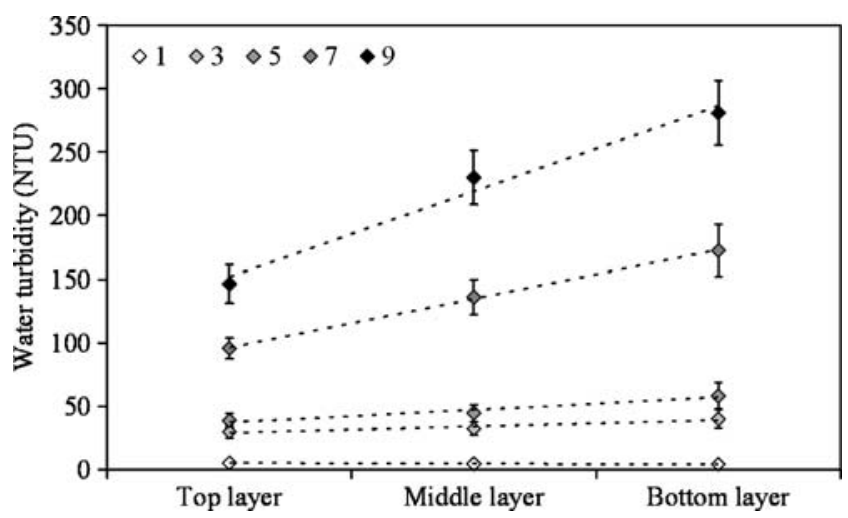

Fig. 1 Average water turbidity in nephelometric turbidity units (NTU) of the upper $10 \mathrm{~mm}$ (top layer), in the middle (middle layer) and of the lowest $10 \mathrm{~mm}$ (bottom layer) of five selected experimental water bodies at 1300 hours. Numbers shown in the legend correspond with the level of turbidity of each water pool, whereby 1 indicates the clear water pool and 9 the most turbid water pool. The error bars indicate the standard error of the mean $(n=11$ days $)$ and for each water pool the regression line is shown (dotted lines) 


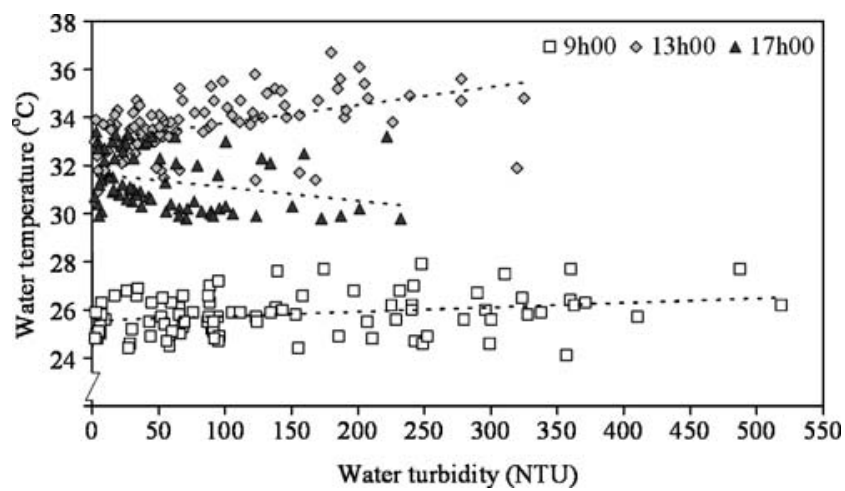

Fig. 2 Relationship between the near-surface water temperature $\left({ }^{\circ} \mathrm{C}\right)$ and the average water turbidity (NTU) of all experimental water bodies over the whole study period at $9 \mathrm{~h} 00$ ( $\mathrm{n}=10$ days), $13 \mathrm{~h} 00$ $(\mathrm{n}=11$ days $)$ and $17 \mathrm{~h} 00(\mathrm{n}=8$ days). For each time the regression line is shown (dotted lines)

were lower than the turbidity readings in the morning at 0900 hours (Mann-Whitney $U$ test, $P<0.001$ ).

The incoming solar radiation load on the two selected consecutive days is shown in Fig. 3. The total incoming short wave radiation load was $23.8 \mathrm{MJ} \mathrm{m}^{-2}$ on the clear day (25 May 2006) and $18.9 \mathrm{MJ} \mathrm{m}^{-2}$ on the overcast day (26 May 2006). The total received incoming solar radiation

a

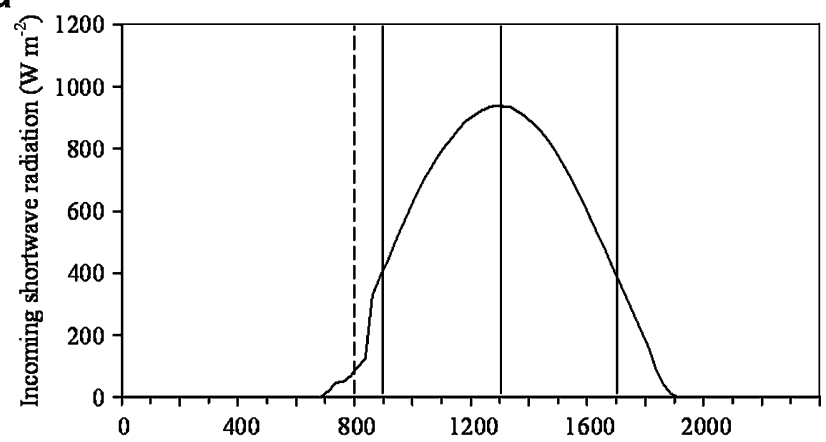

b

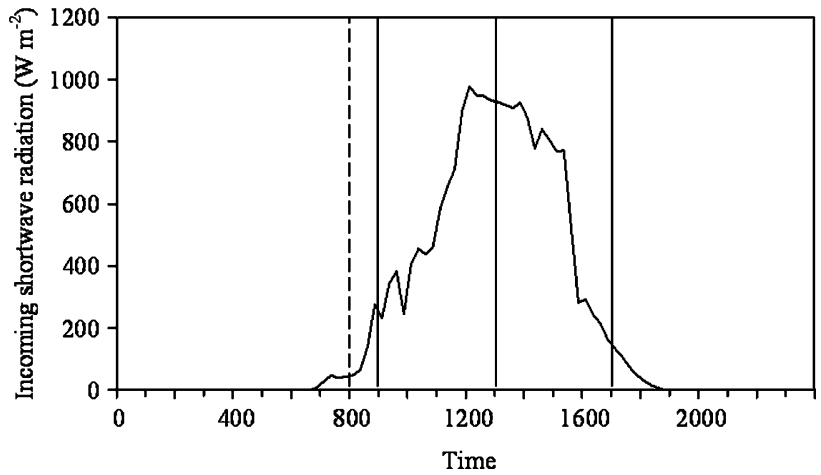

Fig. 3 Incoming short wave radiation $\left(\mathrm{W} \mathrm{m}^{-2}\right)$ on a 25 May 2006, a clear day, and b 26 May 2006, an overcast day. The discontinuous vertical lines indicate the time at which the water of each experimental site was mixed thoroughly (0800 hours), the solid vertical lines when the near-surface water temperature and water turbidity were measured (0900, 1300 and 1700 hours) load at 1300 hours was 12.7 and $10.1 \mathrm{MJ} \mathrm{m}^{-2}$ on the clear and overcast day, respectively. At 1700 hours, these quantities were 22.8 and $18.6 \mathrm{MJ} \mathrm{m}^{-2}$, respectively. The maximum recorded incoming solar radiation is higher on the overcast day, as extra solar radiation reached the earth's surface due to the reflection of radiation by clouds.

The relationship between the near-surface water temperature and the average water turbidity on both selected days is shown in Fig. 4. In the morning, at 0900 hours, no large differences were observed between the measured water temperatures of the various pools. However, at 1300 hours there was a clear positive relationship between water temperature $(\mathrm{T})$ and water turbidity $(\mathrm{Tu})$, on both the clear day $\left(\mathrm{T}=0.014 \times \mathrm{Tu}+33.17, F_{1,7}=165.75, P<0.001\right)$ and the overcast day $\left(\mathrm{T}=0.018 \times \mathrm{Tu}+31.78, \quad F_{1,7}=709.26, P<\right.$ 0.001 ); the top water layer of a pool of a higher turbidity was warmer. The difference between the water temperature of the clearest and of the most turbid water pool was 3.3 and $2.9^{\circ} \mathrm{C}$ on the clear and the overcast day, respectively.

In the late afternoon, at 1700 hours, the water temperature of the most turbid pool was $0.2^{\circ} \mathrm{C}$ lower than that of the clearest water pool on the clear day. On the overcast day, this difference was $1.2^{\circ} \mathrm{C}$ and there was a clear negative relationship between water temperature and water turbidity
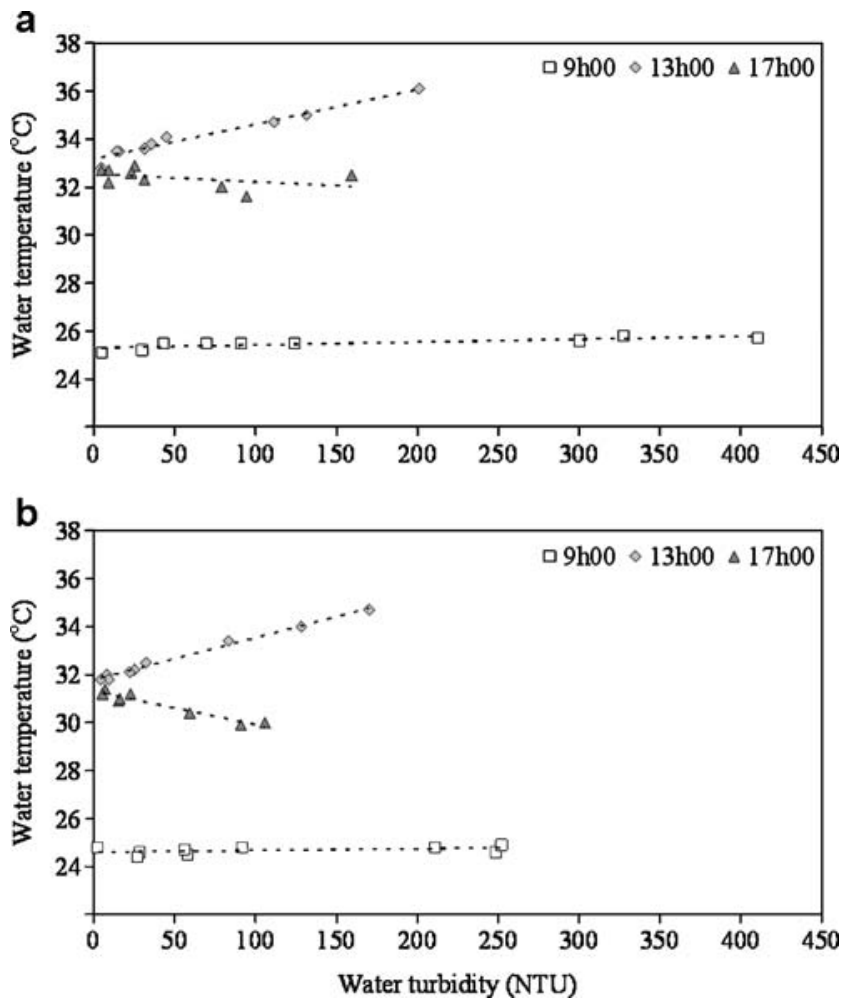

Fig. 4 Relationship between the near-surface water temperature $\left({ }^{\circ} \mathrm{C}\right)$ and the average water turbidity (NTU) of each water pool at 0900 , 1300 and 1700 hours on a 25 May 2006, a clear day, and b 26 May 2006, an overcast day. For each time, the regression line is shown (dotted lines) 
$\left(\mathrm{T}=-0.014 \times \mathrm{Tu}+31.30, \quad F_{1,7}=90.02, P<0.001\right)$. This day experienced a sudden decrease in incoming solar radiation of $488 \mathrm{~W} \mathrm{~m}^{-2}$ in $30 \mathrm{~min}, 1.25 \mathrm{~h}$ before 1700 hours.

Finally, to obtain a better insight into the difference between clear and turbid pools of water, Fig. 5 shows the dynamics of the measured diurnal temperature of a clear water pool of similar dimensions measured during a clear day in the previous year (20 May 2005; K.P.P., unpublished data), as well as the plausible dynamics of the temperature in the pool with the highest turbidity during daytime, based on measurements in the most turbid pool of water during the present study on a clear day (25 May 2006). This illustrates that, apart from reaching a higher maximum temperature, turbid water collections are likely to be warmer than clear pools for a substantial part of the day.

\section{Discussion}

In small tropical pools, suspended soil particles caused enhanced temperatures of the water at midday (1300 hours). This effect was observed during both clear and overcast days. As the daily temperature and turbidity of each pool of water at the start of each experimental day, as well as the daily weather conditions, varied between the days, a comparison of the temperature-turbidity relationship under various weather conditions is not reliable. However, there was a significant overall trend: around midday, the time when normally the maximum incoming solar radiation load reaches the earth's surface, waters that were more turbid had a higher near-surface water temperature. Due to the apparent linear relationship between water turbidity and water temperature, we assume that similar natural pools,

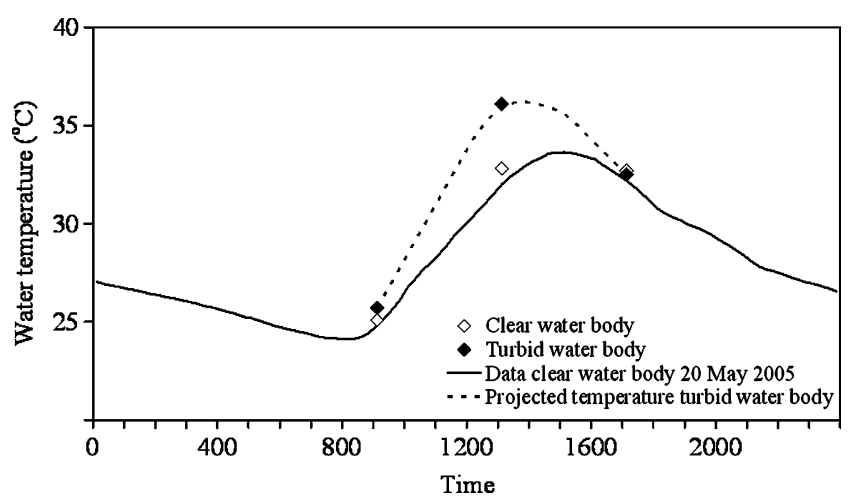

Fig. 5 Water temperature $\left({ }^{\circ} \mathrm{C}\right.$ ) of a clear water pool (with similar dimensions as the water bodies in this experiment) during a clear day in the previous year (20 May 2005), with plotted the temperature data collected from the clearest and most turbid water pool during this experiment on a clear day (25 May 2006). The dashed line shows the plausible temperature dynamics of the most turbid water pool during daytime which are more turbid than the pools studied in this experiment, will be even warmer.

This study only measured water turbidity and water temperature at three time points during daytime. Permanent monitoring of the temperature in turbid water collections will provide us with useful information, such as the maximum water temperature during daytime and the temperature dynamics at night. Our data suggest that the water temperature of turbid pools will be lower than that of clear water during at least a certain part of the late afternoon, as there was an overall negative correlation between the water temperature and water turbidity at 1700 hours. However, it remains to be studied whether this difference is temporary or maintained throughout the night.

Besides an effect on the near-surface temperature, preliminary data showed that a high turbidity of small water collections will result in thermal stratification during daytime (K.P.P., unpublished data), whereby the lower layers will be cooler. As larvae of A. gambiae s.l., which normally live horizontally near the air-water interface, dive and can stay submerged for longer periods (Tuno et al. 2004, 2007), they will experience different temperatures in turbid waters while diving, compared to clear water bodies that are homothermic (Paaijmans et al. 2008). In very turbid water collections, this diving behavior may be a mechanism to escape unfavorably high temperatures near the air-water interface during daytime.

The present study shows the results for a pool of water of one particular size only. In sub-Saharan Africa, immatures of $A$. gambiae s.l. can be found in a wide range of different water pools, which can be smaller, such as human foot-prints and animal hoof-prints, or larger, such as tire tracks, brick-pits and even rice fields. As light can penetrate a turbid water column only to a certain depth (depending on the water turbidity and the amount of incoming light), deeper water collections will have a relatively larger part of this column that is not reached by the light. This part will, as a result, be lower in temperature. When the water column is well mixed, the temperature of a large pool will be lower than the temperature of a very shallow pool, where cooler lower layers are not present, as the light can still reach the bottom. We know that the temperature in small puddles can reach temperatures close to $40^{\circ} \mathrm{C}$ (Jepson et al. 1947; Young and Zimmerman 1956; Rzóska 1961; Weir 1969; Minakawa et al. 1999; Munga et al. 2005). In small and clear water bodies (diameter $0.16 \mathrm{~m}$, water depth $0.04 \mathrm{~m}$ ), the maximum water temperature often reached 38 $39^{\circ} \mathrm{C}$ (Paaijmans et al. 2008). When such water pools are very turbid, even higher daytime temperatures may be recorded. As a consequence, these temperatures may reach or even exceed the thermal death point of the larvae of A. gambiae s.l., which is $42^{\circ} \mathrm{C}$ (Haddow 1943; Jepson et al. 1947). 
Moreover, higher temperatures will result in a higher loss of water due to evaporation. Measurements in a similar clear water pool in the previous year showed an average evaporation rate of $3.8 \mathrm{~mm} \mathrm{day}^{-1}( \pm 0.1$; range 1.6-5.0) (study period of 40 days, March-May 2005). To determine whether more water will vaporize in turbid water bodies during a 24-h cycle, the water temperature dynamics at night in such pools needs to be assessed.

Ye-Ebiyo et al. (2003) observed that the water turbidity in natural puddles increased as the rainy season ended and the diameter of the puddles diminished. We observed that the turbidity of the pools decreased over 1 day. In natural breeding sites this may not be observed, as turbidity is also caused by other particles, such as finely divided organic matter, plankton and micro-organisms. The molecules of these components have their own band of absorption in which light photons of different wavelengths are absorbed. The effect of particle-type on the water temperature needs to be studied in further detail. Moreover, borrow pits are far less transient than are foot/hoof prints and other smaller depressions, and the composition of clay in these sites may be considerably different. However, the water turbidity will change due to rainfall, human or animal disturbance and biological activities in the pool. This may result in a dynamic turbidity over time and should be studied further as well, together with the course of water turbidity over depth.

In summary, this study demonstrates that suspended soil particles can change the temperature of larval habitats of the malaria mosquitoes A. gambiae s.l. Apart from reaching higher daytime temperatures, the diurnal dynamics of the water temperature of turbid water bodies will differ from that of clear water bodies. This will result in a longer exposure of the mosquito immatures to higher temperatures during daytime. As these immatures are cold-blooded, an increase in temperature is likely to increase their development rate. Depinay et al. (2004) showed the relationship between larval development rate of A. gambiae s.l. and water temperature, based on the outcome of various studies in the laboratory and in the field, and estimated that the temperature at which larval development rate is highest is around $37^{\circ} \mathrm{C}$. Development rate decreases sharply at higher temperatures. As the water temperature dynamics during the late afternoon and night were not assessed, it remains unknown whether gains in development during daytime could be offset by a slower development during late afternoon and night-time as a result of relatively cooler conditions.

A better understanding of the relationship between water turbidity and water temperature can improve models that estimate the water temperature of small water pools (e.g., Jacobs et al. 2008). Moreover, a better knowledge of factors that have an influence on the life-history characteristics of the immature malaria mosquitoes is needed, as they will determine the productivity of breeding sites and therefore the increase or decrease in malaria transmission.

Acknowledgements Silvie Huijben is acknowledged for her assistance during the experiments. We like to thank Marcel Dicke, Birol Kara and one anonymous reviewer for their constructive suggestions, which helped to improve this manuscript. This work was supported by the Netherlands Foundation for the Advancement of Tropical Research (NWO/WOTRO; WB093-409) and has been published with permission of the Director of the Kenya Medical Research Institute.

Open Access This article is distributed under the terms of the Creative Commons Attribution Noncommercial License which permits any noncommercial use, distribution, and reproduction in any medium, provided the original author(s) and source are credited.

\section{References}

ASTM (2000) D1899-00 Standard test method for turbidity of water. In: Annual Book of ASTM Standards, Vol. 11.01. Philadelphia, American Society for Testing and Materials

Bayoh MN, Lindsay SW (2003) Effect of temperature on the development of the aquatic stages of Anopheles gambiae sensu stricto (Diptera: Culicidae). Bull Entomol Res 93:375-381

Bayoh MN, Lindsay SW (2004) Temperature-related duration of aquatic stages of the Afrotropical malaria vector mosquito Anopheles gambiae in the laboratory. Med Vet Entomol 18:174-179

Coetzee M, Craig M, Le Sueur D (2000) Distribution of African malaria mosquitoes belonging to the Anopheles gambiae complex. Parasitol Today 16:74-77

Depinay J-MO, Mbogo CM, Killeen G, Knols B, Beier J, Carlson J, Dushoff J, Billingsley P, Mwambi H, Githure J, Toure AM, McKenzie FE (2004) A simulation model of African Anopheles ecology and population dynamics for the analysis of malaria transmission. Malar J 3:29

Fillinger U, Sonye G, Killeen G, Knols BGJ, Becker N (2004) The practical importance of permanent and semipermanent habitats for controlling aquatic stages of Anopheles gambiae sensu lato mosquitoes: operational observations from a rural town in western Kenya. Trop Med Int Health 9:1274-1289

Gillies MT, DeMeillon B (eds) (1968) The anophelinae of Africa south of the Sahara (Ethiopian zoogeographical region). Publication no. 54. The South African Institute for Medical Research, Johannesburg

Gimnig JE, Ombok M, Kamau L, Hawley WA (2001) Characteristics of larval anopheline (Diptera: Culicidae) habitats in western Kenya. J Med Entomol 38:282-288

Gimnig JE, Ombok M, Otieno S, Kaufman MG, Vulule JM, Walker ED (2002) Density-dependent development of Anopheles gambiae (Diptera: Culicidae) larvae in artificial habitats. J Med Entomol 39:162-172

Gross EM (2003) Allelopathy of aquatic autotrophs. Crit Rev Plant Sci 22:313-339

Haddow AJ (1943) Measurements of temperature and light in artificial pools with reference to the larval habitat of Anopheles (Myzomyia) gambiae, Giles, and A. (M.) funestus, Giles. Bull Entomol Res 34:89-93

Huang J, Walker ED, Giroux PY, Vulule J, Miller JR (2005) Ovipositional site selection by Anopheles gambiae: influences of substrate moisture and texture. Med Vet Entomol 19:442-450 
Huang J, Walker ED, Vulule J, Miller JR (2007) The influence of darkness and visual contrast on oviposition by Anopheles gambiae in moist and dry substrates. Physiol Entomol 32:34-40

Jacobs AFG, Heusinkveld BG, Kraai A, Paaijmans KP (2008) Diurnal temperature fluctuations in an artificial small shallow water body. Int J Biometeorol 52:271-280

Jepson WF, Moutia A, Courtois C (1947) The malaria problem in Mauritius: the bionomics of mauritian anophelines. Bull Entomol Res 38:177-208

Kara A, Hurlburt H, Rochford P, O'Brien J (2004) The impact of water turbidity on interannual sea surface temperature simulations in a layered global ocean model. J Phys Ocean 34:345-359

Kara A, Wallcraft A, Hurlburt H (2005) Sea surface temperature sensitivity to water turbidity from simulations of the turbid Black Sea using HYCOM. J Phys Ocean 35:33-54

Kirk JTO (ed) (1994) Light and photosynthesis in aquatic ecosystems. Cambridge University Press, New York

Koenraadt CJM, Paaijmans KP, Githeko AK, Knols BGJ, Takken W (2003) Egg hatching, larval movement and larval survival of the malaria vector Anopheles gambiae in desiccating habitats. Malar J 2:20

Koenraadt CJM, Githeko AK, Takken W (2004) The effects of rainfall and evapotranspiration on the temporal dynamics of Anopheles gambiae s.s. and Anopheles arabiensis in a Kenyan village. Acta Trop 90:141-153

Le Sueur D, Sharp BL (1988) The breeding requirements of three members of the Anopheles gambiae Giles complex (Diptera: Culicidae) in the endemic malaria area of natal, South Africa. Bull Entomol Res 78:549-560

Lyimo EOK (eds) (1993) The bionomics of the malaria mosquito Anopheles gambiae sensu stricto in southeast Tanzania. Adult size variation and its effect on female fecundity, survival and malaria transmission. $\mathrm{PhD}$ Thesis, Wageningen Agricultural University, Wageningen

Lyimo EO, Takken W, Koella JC (1992) Effect of rearing temperature and larval density on larval survival, age at pupation and adult size of Anopheles gambiae. Entomol Exp Appl 63:265-271

McCrae AWR (1984) Oviposition by African malaria vector mosquitoes II. Effects on site tone, water type and conspecific immatures on target selection by freshwater Anopheles gambiae Giles sensu lato. Ann Trop Med Parasitol 78:307-318

Minakawa N, Mutero CM, Githure JI, Beier JC, Yan G (1999) Spatial distribution and habitat characterization of anopheline mosquito larvae in western Kenya. Am J Trop Med Hyg 61:1010-1016

Munga S, Minakawa N, Zhou G, Barrack O-OJ, Githeko AK, Yan G (2005) Oviposition site preference and egg hatchability of Anopheles gambiae: effects of land cover types. J Med Entomol 42:993-997

Mwangangi JM, Muturi EJ, Shililu J, Muriu SM, Jacob B, Kabiru EM, Mbogo CM, Githure J, Novak R (2006) Survival of immature Anopheles arabiensis (Diptera: Culicidae) in aquatic habitats in Mwea rice irrigation scheme, central Kenya. Malar J 5:114
Mwangangi JM, Mbogo CM, Muturi EJ, Nzovu JG, Githure JI, Yan G, Minakawa N, Novak R, Beier JC (2007) Spatial distribution and habitat characterisation of Anopheles larvae along the Kenyan coast. J Vector Borne Dis 44:44-51

Paaijmans KP, Jacobs AFG, Takken W, Heusinkveld BG, Githeko AK, Dicke M, Holtslag AAM (2008) Observations and model estimates of diumal water temperature dynamics in mosquito breeding sites in western Kenya. Hydrol Processes doi:10.1002/ hyp.7099

Robert V, Awono-Ambene HP, Thioulouse J (1998) Ecology of larval mosquitoes, with a special reference to Anopheles arabiensis (Diptera: Culicidae) in market-garden wells in urban Dakar, Senegal. J Med Entomol 35:948-955

Rzóska J (1961) Observations on tropical rainpools and general remarks on temporary waters. Hydrobiologia 17:265-286

Sattler MA, Mtasiwa D, Kiama M, Premji Z, Tanner M, Killeen GF, Lengeler C (2005) Habitat characterization and spatial distribution of Anopheles sp. mosquito larvae in Dar es Salaam (Tanzania) during an extended dry period. Malar J 4:4

Service MW (1973) Mortalities of the larvae of the Anopheles gambiae Giles complex and detection of predators by the precipitin test. Bull Entomol Res 62:359-369

Service MW (1977) Mortalities of the immature stages of species $\mathrm{B}$ of the Anopheles gambiae complex in Kenya: comparison between rice fields and temporary pools, identification of predators, and effects of insecticidal spraying. J Med Entomol 13:535-545

Tuno N, Miki K, Minakawa N, Githeko A, Yan G, Takagi M (2004) Diving ability of Anopheles gambiae (Diptera: Culicidae) larvae. J Med Entomol 41:810-812

Tuno N, Githeko AK, Nakayama T, Minakawa N, Takagi M, Yan G (2006) The association between the phytoplankton, Rhopalosolen species (Chlorophyta; Chlorophyceae), and Anopheles gambiae sensu lato (Diptera: Culicidae) larval abundance in western Kenya. Ecol Res 21:476-482

Tuno N, Githeko A, Yan G, Takagi M (2007) Interspecific variation in diving activity among Anopheles gambiae Giles, An. arabiensis Patton, and An. funestus Giles (Diptera: Culicidae) larvae. $\mathrm{J}$ Vector Ecol 32:112-117

Van Donk E, Grimm MP, Gulati RD, Klein Breteler JPG (1990) Whole-lake food-web manipulation as a means to study community interactions in a small ecosystem. Hydrobiologia 200/201:275-289

Weir JS (1969) Studies on Central African Pans III Fauna and physico-chemical environment of some ephemeral pools. Hydrobiologia 33:93-116

Ye-Ebiyo Y, Pollack RJ, Kiszewski A, Spielman A (2003) Enhancement of development of larval Anopheles arabiensis by proximity to flowering maize (Zea mays) in turbid water and when crowded. Am J Trop Med Hyg 68:748-752

Young FN, Zimmerman JR (1956) Variations in temperature in small aquatic situations. Ecology 37:609-611 